\title{
LA CRISIS DEL CONCEPTO DEL MUNICIPIO COMO ENTIDAD NATURAL
}

I. El criterio jusnaturalista en el Municipio español.

II. Influencias determinantes.

III. Elementos constitucionales.

IV. El error histórico.

V. Aspecto geográfico.

VI. Concepto de lo municipal.

VII. Efectos prácticos: los pequeños Municipios y la autonomia.

VIII. Modos reales de aplicación del sistema.

IX. Su crisis en las legislaciones actuales.

I. Quizás parecerá extemporáneo en los momentos actuales el plantear el problema del concepto del Municipio en relación con los principios jusnaturalistas. Es indudable que esa doctrina ha sido superada por las modernas orientaciones de la filosofía jurídica, pero no es menos cierto que en los últimos treinta años ha ejercido la misma una profunda influencia en nuestro régimen municipal, inspirándose en ella todos los proyectos y todas las realidades legislativas de dicho período, y que aún hoy mismo, a pesar del radical viraje de nuestra evolución política como consecuencia del movimiento nacional, comprobamos la supervivencia de diversos aspectos de aquella tendencia, sin que se haya tenido en cuenta su incompatibilidad esencial con los principios básicos del sistema imperante.

La consideración del Municipio como entidad natural se introdujo en la legalidad vigente en el Estatuto de 1924 (1). El mismo se inspiraba plenamente en los criteriós democráticos de comienzos del siglo y en la definición que contiene del Municipio, como buena parte de su articulado, se limitó a transcribir, casi al pie de la letra. el concepto que establecen los proyectos que fueron sus precedentes inmediatos (2). El texto de la Ley fué, en este aspecto, calurosa-

(1) "Es Municipio la asociación natural, reconocida por la Ley, de personas y bienes, determinada por nécesarias relaciones de vecindad, dentro del término a que alcanza la jurisdicción de un Ayuntamiento." (Art. 1.9 del Estatuto.)

(2) "Forma Municipio la comunidad natural, reconocida por la Ley, de familias y casas dentro del término a que alcanza la jurisdicción de su Ayunta'miento." (Art. 1.9 del Proyecto sobre régimen de Administración Local de 1907.)

"Forma Municipio la sociedad natural, reconocida por la Ley, establecida en un término territorial definido por las relaciones de vecindad $y$ al cual alcanza la jurisdicción de un Ayuntamiento." (Base primera del Proyecto d• 1912.) 
mente subrayado por un preámbulo que proclamaba, como base fundamental de toda la reforma, un fervoroso y decidido criterio jusnaturalista. "El Municipio...-dice dicho preámbulo-no es hijo del legislador: es un hecho social de convivencia anterior al Estado y anterior también y, además, superior a la Ley. Esta ha de limitarse. por tanto, a reconocerlo y ampararlo en función adjetiva... Por todo ello, el nuevo Estatuto admite la personalidad municipal allí donde la naturaleza la engendra, sin establecer requisitos de mero artificio que nunca han tenido posible cumplimiento...".

Esta verdadera profesión de fe jusnaturalista quería significar: una rectificación total del principio en que se inspiraba la vieja Ley de 1877, cuyo artículo $10^{\circ}$ consideraba al Municipio como "la asociación legal de todas las personas que residen en un término municipal", exigiendo el $2 .^{\circ}$, para que el Municipio pudiera considerarse existente, un mínimo de 2.000 habitantes, un territorio proporcionado $y$ recursos suficientes para atender a los gastos obligatorios.

La Ley de 1935, vigente en la actualidad, reproduce, en este particular, como en tantos otros, el articulado del Estatuto, del que fué, en su mayor parte, copia desafortunada. Su artículo $2 .^{\circ}$, repitiendo el concepto de "asociación natural" determinado por el Estatuto, pergeñaba una definición del Municipio, que, como hacemos constar er otro lugar (3), se limitaba a disfrazar, con alteración de palabras, la establecida por el Código municipal de la Dictadura, sin aporta ${ }^{\circ}$ ninguna idea propia.

Así pues, en el momento actual nos encontramos ante una legalidad municipal estrictamente jusnaturalista, que interesa examinar en su origen y en su contenido; no sólo desde un punto de vista exclusivamente teórico, para satisfacer una mera curiosidad de erudito, sino más bien atendiendo a las consecuencias prácticas, de extraordinario alcance, que pueden derivarse de esta situación, estrechamente relacionadas con la postura total del Municipio con respecto al Estado y con los trascendentales problemas de la autonomía y de la existencia de los pequeños Municipios.

II. Los autores del Estatuto, al establecer los fundamentos básicos del Municipio que el mismo regula, se inspiraron en una doctrina que había alcanzado gran predominio durante el pasado siglo, pero que en 1924 ya se encontraba en decadencia. No nos es posible exponer, ni aún en estricta síntesis, el conjunto de teorías que, basadas en principios de Derecho natural, reconocían al Municipio

(3) Véase nuestra "Ley Munieipal Comentada", Madrid, 1935, pág. 21. 
una personalidad propia frente al Estado y un origen independiente de la voluntad de éste. Nos limitaremos a consignar que Zachariae (4) y Bluntschli (5), como tantos otros, reconocían unos derechos fundamentales del Municipio, concediéndoles alcance análogo a los individuales del ciudadano, y reproduciremos seguidamente algunos de los principios del sistema que mayor repercusión tuvieron en nuestra Patria.

Taparelli (6) nos plantea la teoría que denomina de las sociedades "hipostáticas", de incremento en grados sucesivos, en que la asociación de familias constituye el Municipio y la reunión de éstos el Estado. Ahrens (7) coincide con ello en su clásica definición, afirmando que "el Municipio es el segundo grado de las sociedades fundamentales humanas"; y Tocqueville (8) recoge el criterio de la escuela en una fórmula concreta, que copiaremos literalmente por lo bien que refleja el pensamiento romántico del jusnaturalismo de la época. "La Commune-dice este filósofo francés-est la seule association qui soit si bien dans la nature, que, partout où il y a des hommes réunis, il se forme de soi-même une Commune. La société communale existe done chez tous les peuples, quels que soient leurs usages et leurs lois; c'est l'homme qui fait les royaumes et crée les républiques; la Commune paraît sortir directement des mains de Dieu".

Estas teorías tuvieron en España extraordinaria influencia. Las habían recogido los tratadistas de Derecho Natural; pero alcanzaron más amplio desarrollo como consecuencia del-desenvolvimiento logrado en nuestra Patria por los estudios históricos sobre el Municipio medieval. La postura de los Concejos de aquella época, con facultades propias de carácter estrictamente político, frente a un Estado que prácticamente no existía, parecía confirmar, con la experiencia histórica, las teorías jusnaturalistas. Martínez Marina había iniciado esta orientación en los comienzos del pasado siglo, pero es mucho más tarde, en el brillante estudio de Hinojosa (9), donde se evidencia plenamente la postura cuasi soberana de aquellas en-

(4) Zachariae.-Bundesstaatsrecht, vol. I, pág. 71.

(5) Bluntschli.-Deutsches Staatswörterbuch, vol. IV, art. Korperschaften.

(6) Taparelli.-Ensayo teórico de Derecho Natural. Versión española. Madrid, 1.868; vol. III, págs. 254 y' 255 .

(7) Ahren.-Curso de Derecho Natural. Versión española. Madrid, 1878; página 507 .

(8) Toqqueville (A. de).-La Démocratie en Amerique, Paris, 1874.

(9) Hinojosa (Eduardo).-Origen del régimen nunicipal de León y Cas. tilla. Conferencia pronunciada en el Ateneo de Madrid en el curso de 1895 a 1896. 
tidades. Azcárate, anteriormente, había deducido también consecuencias análogas de la revolución municipal de los siglos XII al XIV, llegando a la conclusión clásica del jusnaturalismo de que "el Municipio es una sociedad natural anterior a la voluntad del Estado y de los individuos, y cuya existencia y relaciones necesarias con los círculos superiores tienen por tanto que reconocer, no crear, el Estado y los individuos" (10).

Precisa, asimismo, tener muy en cuenta como factor trascendental en la formación del concepto jusnaturalista de nuestro $\mathrm{Mu}$ nicipio, los estudios de derecho consuetudinario llevados a cabo, bajo la dirección de Joaquín Costa, en los últimos veinte años del pasado siglo. Se hizo patente en aquellos trabajos, como una verdadera revelación, la subsistencia al margen de la Ley escrita, en muchas aldeas de León y de Asturias, de una administración propia de tipo de democracia directa, constituyendo una interesante supervivencia medieval. Costa declaraba en dichos trabajos que, en materia municipal, "el legislador debe limitarse a ser mero intérprete del estado social y una como cámara obscura, sin voluntad propia, que reproduzca con fidelidad los rasgos fisiognómicos del Municipio tal como es...; un principio de biología jurídica, confirmado por la experiencia de todos los siglos, declara cómo la realidad es anterior y superior a la Ley; cómo, por consiguiente, el molde de aquélla no es el de ésta, sino al revés..." (11).

Las conclusiones establecidas por los investigadores a que nos referimos tuvieron una trascendencia inusitada e influyeron decisivamente en la caracterización legal de nuestro Municipio. El criterio de que debían subsistir las pequeñas municipalidades se recoge ya en. el proyecto de Bases para la reforma de la Ley Municipal de 1891, y más tarde, en los de 1907 y 1912, se perfila como hemos visto, con plenitud de contenido, todo el planteamiento jusnaturalista del problema del Municipio.

Para completar la enumeración de las fuentes determinantes de! sentido del Estatuto de 1924, no debe omitirse una muy acentuada influencia trasatlántica. No nos referimos ahora a las repercusiones del formidable movimiento municipalista llevado a cabo en los Estados Unidos en los primeros años del presente siglo, tanto en el

(10) Azcárate (Gumersindo de).-El Municipio en la Edad Media. Estudios filos6ficos y polfticos. Marid, 1877; pág. 207.

(11) Derecho Consuetudinario y Economía Popular de España. Barcelona, 1903; tomo I. Prólogo de Joaquín Costa, reproducción del publicado en 1885 con. el folleto "Materiales para el estudio del derecho municipal consuetudinario de España. 
aspecto doctrinal como en el legislativo. Sus efectos en nuestro Estaiuts fueron sin duda profundos y trascendentales; pero en lo que constituye el tema de este trabajo no pudieron tomarse en cuenta las tendencias dominantes en América del Norte, inspiradas en in criterio de absoluta oposición a toda veleidad naturista (12). Es, en cambio, indiscutible que en la redacción del preámbulo y del artículo 1.9 del Estatuto municipal de la Dictadura pesó de modo decisivo el pensamiento que orienta la Ley Municipal de Cuba de 29 de mayo de 1908, la cual constituye la más perfecta experiencia de. las teorías de su autor, el Profesor Carrera Justiz, quien representa en la actualidad la más genuina y extremada supervivencia de la escuela de! jusnaturalismo municipalista (13). Es indudable que el artículo 11 de aquella Ley (14) ha servido de base para la redacción del párrafo tercero del preámbulo del Estatuto que hemos citado con anterioridad.

Los antecedentes españoles estrictamente municipalistas son bien escasos. Estas cuestiones han sido en España, durante mucho tiempo, tema que en general no despertó más curiosidad que la puramente política, en el sentido menos elevado de la expresión. Destaca, sin precedentes ni continuación hasta la fecha, el meritorio trabajo del Profesor Posada (15), en el cual se han iniciado en los pro. blemas de ia ciudad, en los últimos veinticinco años, cuantos en España quisieron estudiarlos, siendo esa obra, para los más de ellos, ei único bagaje intelectual que les fué asequible en esa especialidad. De indudable influencia en la evolución municipal española contem-

(12) Una característica resolución de la Corte Suprema de los Estados Unidos dice textualmente que "las Corporaciones municipales son subdivisio nes politicas del Estado creadas como medios para ejercer las funciones gubernamentales que el Estado tiene a bien confiarles'.-Lespes (Jules).-Le Gouvernement Local aux Etats-Unis. Bruselles, 1930; pág. 89.

"En derecho ingles y americano una municipalidad es una autoridad loca! subordinada creada por el Gobierno central y revestida de los atributos juridicos de la Corporacion..."-Fairlie' (John A.).-Municipal Administration. Prefacio.

(13) “... Donde quiera que este exista [el hecho social del Municipio] y (a) como existiere, all hay una "personalidad" que necesita ser reconocida por. el legislador para facilitarle la vida del derecho. De ahi lo que conocemos por derecho de "personalidad" que es algo innato, inalienable e imprescriptible en su más elevada concepción... Ese es el derecho natural; es la enseñanza de la naturaleza..."-Carrera Justiz (F.).-El Derecho páblico y la autonomía munieipal. Habana, 1913 ; páfs. 31 y 32 .

(14) "Art. 11. Donde quiera que exista una agrupación de habitantes cuya comunidad de vida determine relaciones de vecindad, y sobre una extension sïperficial separada de otros censos de población. será procedente la organiza¿isin municipal."

(15) Posaila (Adolfo).- Fl régimen munícipal de la ciudad ni,derna. Madivid, 1916. 
poránea, aportó a ella la tendencia jusnaturalista de su autor, que.. ya se percibía claramente en la edición de 1916, y que alcanza una. completa y entusiasta formulación en la de 1927 (16).

III. Expuestos ya los antecedentes del problema, será preciso que planteemos expresamente los términos del mismo, ocupándonos de sus fundamentos esenciales y de las consecuencias prácticas de su aplicación en la realidad legislativa, para poder formular, comc, consecuencia de ello, una crítica adecuada de las soluciones españolas en esta materia.

Estimamos que un análisis detenido de las características esenciales de la idea municipal jusnaturalista obligará a distinguir en la misma tres elementos bien diferenciados, que no faltan en ninguna de las exposiciones doctrinales de la escuela:

a) Aspecto bistórico.-Se admite una prioridad en el tiempo del Municipio sobre el Estado. "El Municipio, como la familia, existieron antes que el Estado-dice Royer Collard (17)—. La Ley política lo ha encontrado de hecho constituído y no lo ha formado". De ello resulta que el Estado es una consecuencia no necesaria del Municipio, por lo cual, según' los mantenedores de ese sistema, "se comprende un Municipio sin Estado nacional...; pero no se comprende un Estado nacional sin Municipio" (18).

b) Aspecto geográfico - Es característica del Municipio natural, tal como lo entienden sus propugnadores, la contigüidad material de familias y de edificios que determinan la vecindad, constituyendo una agrupación perfectamente individualizada en el espacio; con lo cual, necesariamente ha de coexistir una organización jurídica de gobierno. Así vemos que Ahrens (19), destacando la importancia fundamental del elemento geográfico, considera al Municipio como "una comunidad localizada de familias e individuos"; y que Taparelli (20), en la evolución histórica que establece, designa con el nombre de tribu al simple agregado de familias y sólo le otorga categoría de Municipio cuando la tribu tiene "residencia fija". Por otra parte, esa convivencia de familias, geográficamente localizada, se entiende siempre como aglomeración de viviendas, puesto que las "relaciones de vecindad" con que unánimemente caracterizan a! Mu-

(16) Define Posada el Municipio "como el núcleo social de vida humana total, determinado o definido, naturalmente, por las necesidades de la vecindad". Ob. cit.; edición de 1927; cap. II-V, pág. 52.

(17) Citado por Rodrígiez Martín (Antonio).--Régimen de autonomía municipal. Madrid, 1919; pág. 47.

(18) Carrera Justiz, ob. cit.; pág. 35.

18 (19) Ahrens; ob. cit.; pág. 622 . 
nicipio las leyes jusnaturalistas (21) sólo en la convivencia urbana: puede lograrse (22). Así lo expresa gráficamente Miliouche (23) cuando define el Municipio como "agregat de feux", añadiendo después que el mismo "debe representar una unidad geográfica compacta" (24) ; ello coincide exactamente con los preceptos legales en vigor, y así vemos cómo la Ley de 1935 establece la contigüidad de edificaciones como base fundamental para que pueda reconocerse dónde existen las relaciones de vecindad que exige su artículo $1 .^{\circ}$ para que haya una entidad municipal (25).

c) Aspecto juridico.-La escuela jusnaturalista no se contenta con determinar, como hemos visto, la realidad social que es base de su doctrina. Quiere obtener resultados prácticos de la misma, y completa su tesis con un postulado ineludible: en donde esta realidad se ofrezca, y coexistiendo con ella, existirá fatalmente un organismo propio de gobierno dotado de personalidad autónoma.

El fundamento filosófico del criterio indicado se basa en el supuesto de la existencia de una materia genuinamente municipal, totalmente diferenciada de la que pertenece al Estado, que constituye el contenido necesario del Municipio. Si no existiera esa competencia privativa, toda la doctrina jusnaturalista se desmoronaría, puesto que no podría comprenderse una personalidad sin fines.

El Municipio jusnaturalista, para sus sostenedores, es una sociedad total. Como dice Ahrens (26), "abarca todos los aspectos de la personalidad humana..., para la persecución de todos los fines esenciales de la vida". Esto lo confirma Miliouche (27), afirmando que "como persona moral, el Municipio tiene intereses propios, lo mismo que toda persona moral o física".

Las consecuencia de estos principios son evidentes. Así pues, pro-

(21) Véanse los artículos $1 .^{\circ}$ de la Ley de Cuba de 1908 y del Estatuto de 1924 y $2 .^{\circ}$ de la de 1935.

(22) Se entiende por vecindad, según el Diccionario de la Real Academia Éspañola, "el conjunto o número de vecinos de un pueblo o barrio", y por vecino, "al que habita con otros en un mismo barrio, casa o pueblo".

(23) Miliouche (Bogdan).-L'organisation municipale en Yougoslavie. París, 1934 ; pág. 64 .

(24) Miliouche, ob. cit.; pág. 78.

(25) "Art. 9.9 No podrá autorizarse la constitución de nuevo Municipio cuando el núcleo poblado que trate de segregarse se hallase unido por calle o zona urbana al término municipal originario." "Art. 13: El Gobierno podrá acordar la incorporación a Municipios de más de 100.000 habitantes de aquellos grupos de población que dependan de otros Ayuntamientos cuando el desarrollo de las edificaciones llegue a confundir los nucleos urbanos..." Ley Municipa de 1935 .

(26) Ahrens, ob. cit.; pág. 507.

(27) Miliouche, ob. cit.; pág. 73. 
baremos con Romagnosi (28) "cómo conserva el Municipio su autoridad propia, enteramente distinta de las derivadas $a b$ alto...". Y ya en este terreno, podremos llegar sin esfuerzo alguno a las más extremas deducciones. Admitido el principio, todas las consecuencias son posibles. Observaremos, como dice Carrera Jústiz (29) que "el Municipio es el Estado en lo local", y como Carnevalli (30) afirma, que "colocado el Municipio como institución de derecho frente a la autoridad del Gobierno... se halla situado fuera de la jerarquía y no puede jurídicamente sufrir actos de imperio sino en los casos... autorizados por la Ley por razones de orden público...".

IV. Vamos ahora a analizar particularmente cada uno de los tres aspectos enunciados, que entrañan la razón de ser de la doctrina jusnaturalista del Municipio: Comenzaremos por aquél que se basa en los antecedentes históricos y haremos constar que la prioridad en el tiempo de la ciudad municipal sobre el Estado no aparece en la historia; esto es simplemente una fantasía. Kelsen plantea el problema con claridad meridiana: "si la comunidad parcial hoy existente como Municipio hubiera precedido al Estado-dice este autor (31) - es que el Estado habría coincidido con el Municipio, es decir, el Municipio habría sido Estado". Esta es la realidad.

El equívoco nace al considerar algunos el caso peculiarísimo de la ciudad griega, al parecer núcleo urbano independiente de todo Estado a la moderna. Pero téngase en cuenta que la Grecia antigua, como dice Glotz (32), "toda ciudad, por pequeña que sea es un Estado"; y considérese además que el llamado Municipio griego no se presenta nunca en la forma de un simple agregado de familias, como un núcleo unitario de convivencia; ese pretendido Municipio, que como vemos es en realidad un verdadero Estado, es además un Estado terriblemente complejo, una confederación de pueblos y aldeas esparcidos en un territorio extenso (33), con Gobiernos rudimentarios; "por encima de estos Gobiernos locales estuvo el Gobierno central de la ciudad" (34). Los demos constituían los Municipios propiamente dichos, en el sentido moderno de la palabra, con vida

(28) Romagnosi-Oeuyres posthumes. Tome IV, págs. 540 y siguientes.

(29) Carrera Jústiz, ob. cit; pág. 33.

(30) Carnevali (Tito).-II Comune. Nuovi studi. Torino, 1908; pág. 64.

(31) Kelsen (Hans).-Teoria general del Estado. Version española. Barcelona, Madrid. Buenos Aires, 1934 ;pág. 245.

(32) Glotz (G.).-La ciudad griega. Versión española. Earcelona, 1929: página 40.

(33) Fustel de Coulanges.-La ciudad antigua. Version española. Madrid, iз3i: págs. 17 i. 178 y 180.

(o4) Idem, ob. cit.; pág. 182 . 
jurídica y localización topográfica perfectamente diferenciadas de la polis en que se hallaban encuadrados, siendo algunos de ellos tan importantes como Acharnes. en el Atica, que tenía unos 12.000 habitantes (35).

$\mathrm{Y}$ remontándonos a más remotas edades, observaremos también la realidad histórica en pugna, en absoluto contraste con los principios clásicos de la evolución natural y gradual de grupos pre-estatales. Está demostrado que las agrupaciones primitivas son los clanes totémicos, los cuales, "contrariamente a lo que pudiera creerse, no son divisiones locales, es decir, formas primitivas de organización territorial; la comunidad de aldea o, empleando una expresión todavía menos científica, la proximidad en el espacio, no parece, en efecto, ser un modo originario de agrupamiento de los hombres" (36). $\mathrm{Y}$ cuando el clan se fija al territorio, no lo hace en forma de comunidad agrupada, sino en zonas extensas diseminadas-como el nomo ogipcio-, verdaderos Estados en embrión comprensivos de un territorio y una metrópoli o centro fortificado (37).

El sistema jusnaturalista clásico de los ciclos sucesivos, en el estado actual de la ciencia no puede defenderse seriamente. Febvre (38) lo considera "pura novela, pura ilusión retrospectiva", y afirma después, hablando del Estado, que "esta sociedad política, en su amplio sentido, la encontramos por todas partes; bajo su acción y su control se organizan las diversas sociedades conyugales las familias, las aldeas, agrupaciones que llamamos primitivas y que en realidad son moldeadas por ella y a las que, en el fondo, es anterior, puesto que preside lo que se puede llamar su formación". Eduardo Meyer, después de un perspicaz estudio. sienta una rotunda afirmación sobre la preexistencia entre las agrupaciones menores y el Estado: "el Estado-dice este autor (39) - no ha surgido de tales agrupaciones; éstas son las que, por el contrario, han sido creadas por el Estado".

V. Como hemos visto, constituye una de las bases fundamentales de la doctrina que estudiamos la afirmación de que el Municipio natural se determina materialmente como un todo homogéneo e in-

(35) Haussoullier (B).-La vie municipale en Attique. Essai sur l'organisation des démes au quatriéme siécle. París, 1884.

(36) Moret (A.).-De los clanes a los imperios. Versión española. Barcelona, 1925 ; pág. 17.

(37) Moret (A.).-El Nilo y la civilización egipcia. Versión española. Barcelona, 1927 ; págs. 50 y 51.

(38) Febvre (Luciano).-La tierra y la evolución humana. Versión españ jla. Barcelona, 1925; págş. 203 y 204.

(99) Meyer (E.).-Histoire de l'Antiquite. Tomo I. Intrudction a l'étude des :iocietés anciennes. Evolution des groupements humains. Versión francesa. París 1912; pág. 36. 
dividualizable. Para los jusnaturalistas, el Municipio coincide con la ciudad hasta identificarse con la misma, y razonan y proceden como si la convivencia vecinal se presentase siempre en esa forma simple y elemental, perfectamente delimitada. Pero las relaciones sociales ofrecen, generalmente, una mayor complejidad que impide esa coincidencia-esencial en el sistema-entre la aglomeración vecinal-hecho social-y el Municipio-institución jurídica-. En numerosas ocasiones, en presencia de diversos y contradictorios elementos, será muy difícil determinar cuál de ellos constituye la base social a la que haya de adherirse la institución jurídica para determinar, con su coincidencia, la entidad municipal. Habrá de ser la Ley quien se pronuncie entre las distintas soluciones posibles, estableciendo condiciones y reglas, con lo cual habrá caído por su base el sistema naturalista, y nos encontraremos, prácticamente, ante el denominado Municipio legal. Veamos cómo ocurre esto.

En los países de población diseminada se llega, como es sabido, a una atomización de la residencia, prácticamente indefinida. Muchas veces no existe más convivencia vecinal que la de la aldea; otras, ni aun esto, presentándose extensos territorios en una dispersión de viviendas aisladas en que cualquier aglomeración, aún la más elemental, es totalmente desconocida.

Examinemos un caso concreto, que puede ser, perfectamente, la región gallega. Cuenta la misma un total de 319 Municipios; ahora bien, ello, socialmente hablando, no significa nada, porque en Galicia, como hace constar Villar Grangel en su interesante trabajo (40), "el Municipio no es, ,como sucede en otros lugares, el primer germen de la organización social... sino un grado intermedio de las organizaciones locales, que se manifiestan como base social, por debajo y a pesar de las normas legislativas". El Municipio actual en Galicia es una entidad artificial, y realmente no podía ser otra cosa a pesar de todas las teorías. La realidad se impone a todas las elucubraciones filosóficas, y la realidad es que en aquellos territorios existen-frente a 131 ciudades y villas-30.089 lugares $y$ aldeas (41) con vida propia y diferenciada-muchísimos de los cuales sólo tienen 50,40 ó 30 casas, y otros, 20,10 y aún menos-, y

(40) Villar Grangel (Domingo).-El Municipio en Galicia. Conferencia prorunciada en la Semana Municipal de Barcelona el día 15 de julio de 1919. Barcelona, 1919; pág. 7 .

(41) Presidencia del Consejo de Ministros. Dirección General del Instituto Geográfico, Catastral $y$ de Estadistica. Anuario Estadístico de España 1934. Madrid, 1935 ; pág. 22. 
fácil es el comprender que por muy arraigada que sea una convicción jusnaturalista, no se pretendería llegar a la disparatada solución de considerar Municipio a ese polvo social sin contenido propio y sin posibilidad de subsistir, esparcido a voleo por todos los ámbitos del país gallego.

Pero si quisiera llevarse a sus últimas consecuencias el principio jusnaturalista y conceder la categoría municipal a todos esos ínfimos grupos de habitaciones, no habríamos logrado tampoco el reconocimiento de la convivencia natural de vecinos, porque esa convivencia no se manifiesta en Galicia en las aglomeraciones de viviendas, sino en la "parroquia", verdadero organismo básico de la vida rural gallega, núcleo espiritual y sentimental de convivencia y centro de la existencia civil. El gallego se siente miembro de su parroquia, babita en su aldea e ignora el Municipio. Como dice Villar Grangel (42), "ferias, contrataciones, arrendamientos, foros, fiestas, aprovechamientos, registro civil, registro de la propiedad, asociación agrícola, seguros, cultivos, riqueza, costumbres, las necesidades todas de la vida en común, puede decirse que se designan y satisfacen con carácter peculiar en cada parroquia". Ahora bien, la parroquia es un diseminado de aldeas, es un núcleo de convivencia sin contigüidad natural alguna, bien difícil de encajar en los postulados jusnaturalistas que anteriormente hemos expuesto; y por otra parte, en Galicia hay 3.785 parroquias, con una población que oscila entre 300 y 400 habitantes (43) y muchas veces menos; con lo cual, el reconocimiento de su categoría municipal había de crear verdaderos problemas por su insuficiente capacidad económica. Sea como fuere, ante esa gama de matices sociales, habrá de ser la Ley quien determine dónde está el Municipio y fije las condiciones para su existencia. Ello será, en todo caso, una declaración arbitraria. y fuera de los límites que fije la misma siempre quedará un númerc considerable de núcleos de convivencia social con una categoría subalterna que será consecuencia del precepto legal.

Veamos ahora cómo se plantean estos problemas en las grandes aglomeraciones. Consideremos atentamente lo que ocurre en las mismas con respecto a la individualización del núcleo de habitabilidad y su posible coincidencia con el organismo jurídico de gobierno local.

(42) Villar Grangel, ob. cit.; pág. 12.

(43) Datos de las estadísticas oficiales de 1919. 
Tampoco aquí las cosas se dan sencillas. La contigüidad de edificios y la comunidad de intereses sociales se presentan en la periferia de las grandes urbes en manifestaciones confusas y mudables que obligan siempre a determinar el Municipio por una declaración legal, que en ningún caso podrá inspirarse en exterioridades naturales. En esas zonas, producto de la civilización contemporánea y de cada vez mayores en número y en intensidad, el Municipio natural sa esfuma, se desvanece, no puede concretarse.

Es sobradamente conocido para que intentemos plantearlo ahora, el fenómeno de la extensión periférica de las grandes ciudades; lenta, pero inexorablemente, sus edificaciones llegan a desbordar los límites jurisdiccionales del Municipio, a infiltrarse en las órbitas contiguas $\mathrm{y}$, finalmente, a ponerse en contacto con las construcciones de otros centros habitados, dotados de independencia municipal; se termina por no coincidir las fronteras jurídicas de la ciudad con el territorio real de la misma, y entonces se produce una situación confusa, difícil de solucionar con la aplicación estricta de los principios jusnaturalistas. Unas veces se desemboca en la fusión, en la absorción jurídica, que es en resumen una infracción patente de dichos principios, a los que no puede dárseles una interpretación estrictamente topográfica, puesto que existe un carácter local, una genuina espiritualidad, unas características particulares, unos hábitos de convivencia que constituyen la propia individualidad social, al margen de cualquier manifestación externa, elementos todos ellos que han de atropellarse violentamente al establecer una agregación for.. zosa. En otras ocasiones-en muchas-se mantiene la separación de jurisdicciones, la duplicidad de Municipios yuxtapuestos, que ma.. terialmente son una sola unidad. determinándose la situación ab. surda que apunta certeramente Henri Sellier. "Los servicios públi.. cos, para la organización de los cuales cada Municipio posee plena autonomía-dice este ilustre municipalista, considerando una situilción análoga a la que nosotros indicamos-, no pueden someterse a una concentración, técnicamente imprescindible; se aseguran en con. diciones particularmente onerosas y diferentes de un Municipio a otro; un industrial, modificando algunas docenas de metros el emplazamiento de sus talleres, verá variado el precio del gas o de la electricidad que utiliza como primera materia, porque están colocados bajo diferentes autoridades. Basta que las corporaciones administrativas que dirigen los Municipios posean opiniones políticas contradictorias, para que por sus desconfianzas recíprocas agraven 
esta situación, rehusando sistemáticamente... toda coordinación de sus esfuerzos" (44).

Pero aún sin producirse esa confusión de jurisdicciones y de edificios, tropezamos en la periferia de las grandes urbes con situaciones confusas en que el Municipio natural se esfuma, en que la sociedad natural no puede determinarse, en que las agrupaciones de viviendas son una cosa y los intereses vecinales otra distinta, al margen de la convivencia inmediata, no quedando más remedio que la solución arbitraria de la Ley.

Es conocido el sistema de vida de los habitantes de la zona de los alrededores de las grandes ciudades, que les convierte en emigrantes cotidianos que van y vienen del lugar donde residen al lugar donde trabajan. Este flujo y reflujo formidable de obreros, campesinos y funcionarios determina, como dice Sellier (45), que "cada habitante de la banlieu tenga en realidad una doble vida, una vida central y otra periférica, y evidentemente es ilógico que la organización administrativa le haga imposible toda influencia sobre la administración de las diferentes partes de la aglomeración". ¿ Fn dónde, pues, encontraremos el Municipio natural, la razón de convivencia, en esos núcleos materialmente distintos, socialmente idénticos?; $i$ es posible mantener como agrupaciones jurídicas independientes a esas aglomeraciones periféricas, verdaderos cuerpos sin alma, cuyo vecindario sólo las utiliza para sus horas de inactividad y obligado reposo?

Las relaciones sociales han adoptado en nuestro siglo formas de extraordinaria amplitud, determinadas por el desarrollo de la técnica, que ha creado factores que no pudieron ser previstos por los románticos del jusnaturalismo, los cuales se inspiraban en una visión puramente doméstica de la convivencia social. Las facilidades de comunicación, incrementadas en gigantescas proporciones, llevan a localizar el contacto diario de los seres humanos en amplias zonas. más bien territoriales que urbanas. Al hablarse de urbanismo, puede actualmente referirse la expresión, más bien que a una agrupación concreta a extensos territorios con una estrecha solidaridad de intereses, con problemas urbanos comunes y con una verdadera convivencia vecinal, a pesar de estar constituídos por varias aglomeraciones bien diferenciadas materialmente. Ello ha de regularse por

(44) Sellier (Henri).-Les Grandes Agglomérations. Rapport Général au IIl (Yongreg International des Villes. París, 1925; pág. 114.

(45) Sellier, ob. cit.; pág. 118. 
amplias fórmulas jurídicas, y por tanto, frente al criterio restringido del Municipio clásico, empequeñecido por consideraciones meramente idealistas, ha surgido el supermunicipio, la región urbana, la $G$ rosskneis germánica, con realizaciones verdaderamente espléndidas, entre las que destacan las de la cuenca del Ruhr, principalmente la Landesplarungsierband Düsseldorf y las de Merseburg.

VI. Veamos ahora si podemos encontrar al Municipio un contenido propio, requisito indispensable de toda personalidad y funda. mento básico de la entidad local jusnaturalista. ¿Qué es lo municipal?; ¿ existe lo municipal con una caracterización uniforme y constante en el tiempo y en el espacio?; ¿ puede establecerse una diferenciación esencial de contenido entre Municipio y Estado? Este es el problema.

Si examinamos los preceptos enumerativos de competencia de las Leyes municipales modernas y establecemos un parangón entre los mismos y la competencia general del Estado, observaremos una coincidencia esencial de contenido que gira en torno de la idea del servicio público atendido por el Municipio, sin distinción de matices, en tanto en cuanto no haya sido retenido por el Estado. El texto de la Ley alemana de 1935 es concreto y expresivo. "Los Municipios - dice su artículo $2 .^{\circ}$-tienen por misión conseguir el bienestar de sus habitantes... Les corresponde llevar a cabo todas las funciones de orden público.... en la medida en que la realización de esas funciones no haya sido confiado por disposiciones legales a otras autoridades..." Nuestra Ley de 1935, a la vuelta de prolijas enumeraciones de competencia, ha de terminar por reconocer la conformidad esencial de contenido de Estado y Municipio en un artículo característico y aleccionador: el 103, que dice así: "La competencia municipal no será obstáculo para las obras y servicios análogos que estén a cargo del Estado, Región o Provincia".

Esta competencia varía a compás de las circunstancias históricas y políticas; pero en todo tiempo existe una amplia zona de contacto en que la esfera de acción del Municipio y la del Estado se superponen y confunden.

Consideremos una época bien característica en el Municipio español: el reinado de Carlos $I$, verdadero período de transición de la autonomía medieval a la centralización absolutista, y veamos de qué modo describe un historiador (46) la competencia de un Cabildo de la época: "Administraba las rentas de propios, disponiendo además

(46) Fcriández Duro) (Cesáreo).-Memorias históricas de la ciudad de Zamora, su provincia y obispado. Madrid, 1882-1883; tomo III, págs. 463 y 464. 
de las generales, repartimientos, sisas, pontazgos, con cuyo producto atendían a las obras públicas de la ciudad y a las de primera necesidad de la tierra, como puentes y calzadas y al servicio del reino, según lo votado en las Cortes. En el ramo que hoy llamamos de Fomento, atendían con interés a la repoblación del arbolado, a la conservación de la caza y la pesca, a la cría caballar y al auxilio de los labradores en plagas y calamidades... En el de Instrucción pública no tenían gran cosa que hacer, toda vez que no había en la ciudad más que una cátedra en que se leía gramática. En beneficencia sostenían los hospitales de fundación particular, la Alhóndiga del pan y e! médico y el cirujano titulares, fomentando en cambio en Industria la muy importañte de paños y mantas, las de icurtidos, lienzos, encajes, cerrajería, sedas, harinas, para todas las cuales habían hecho sabias ordenanzas y traído, en particular de alguna, maestros de Flandes. En punto a milicias, levantaban compañías siempre que era menester, con las prerrogativas de elegir y nombrar los capitanes...". Nada de esto-a lo que hay que añadir el servicio de abastos (47)nos muestra una materia municipal propiamente dicha. Aquí como en todas partes, nos encontramos frente a la noción del servicio público compartido con el Estado en la medida en que éste lo autoriza.

No obstante, ha querido destacarse, entre las infinitas variantes de la competencia municipal, algo constante e inalterable, que con la denominación de "policía urbana", se estima contenido privativo del Municipio. "Policía, vialidad, salubridad; he aquí los servicios municipales a comienzos del siglo XIX-dice Leroy (48) -; la lista era reducida y celosamente conservada dentro de esta estrecha especialidad". Pero ni aún esto, con ser tan poco, podría afirmarse de un modo absoluto. Así, por ejemplo, el Conde de Floridablanca (49) nos describe minuciosamente la actuación directa del poder central en los problemas urbanísticos del siglo XVIII. Podríamos multiplicar las citas; pero si no queremos remontarnos tanto, y saliendo al paso de quienes puedan ver en la labor admirable de Carlos III una intromisión abusiva del absolutismo, buscaremos en plena República española, para comprobar en la base $3 .^{2}$ de la llamada Ley de Coordinación sanitaria de 11 de julio de 1934 la declaración expresa -bien característica en un Estado que había considerado la auto-

(47) Desdevises du Dezert (G.).-L'Espagne de l'Ancien régime. Les Institutions. París, 1889; pág. 92: "La 'cuestión del aprovisionamiento de las ciudades ha sido siempre el principal asunto de los Municipios."

(48) Leroy (Maxime).-La Ville Francaise. París, 1929; pág. 139.

(49) Floridablanca (Conde de).-Memoria presentada al Rey Carlos III y repetida a Carlos IV por el... renunciando al Ministerio. Biblioteca de Autores Españoles. Tomo 59, págs. 331 a 333 . 
nomía municipal como elemento básico de su constitución políticade que era imposible diferenciar las respectivas esferas de acción del Estado y del Municipio en materia de tan constante y exclusiva tradición municipalista como la sanitaria. "La Sanidad-determina la referida base-será una función pública de colaboración reglada de actividades municipales, provinciales y estatales bajo la dirección técnica y administrativa del Estado".

La materia municipal, en un sentido propio y exclusivo, no puede determinarse. La competencia de los Municipios es un producto de las circunstancias históricas y políticas de cada momento, libremente interpretadas por la voluntad del poder central expresada en leyes. La realidad es, prescindiendo de todo género de sutilezas, que el Estado confía una parte del contenido que le es propio a los diversos elementos locales que utiliza para llevar a cabo sus fines, y, como es natural, condiciona y altera a voluntad esa esfera de acción que libremente otorga.

VII. Además del estudio que acabamos de realizar de los fundamentos básicos del criterio jusnaturalista aplicado al Municipio, interesa conocer cuáles sean las consecuencias prácticas del sistema, y de ello vamos a ocuparnos ahora.

“El nuevo Estatuto-dice, como hemos visto, el preámbulo del de 1924-admite la personalidad municipal allí donde la naturaleza la engendra..."; y precisando más ese concepto, añade que la convivencia vecinal, que la Ley debe limitarse a reconocer y amparar, "se da en núcleos de gradación ilimitada, desde los insignificantes que sólo constan de unas docenas de vecinos, hasta los gigantescos que cuentan por millones sus habitantes...”. Es decir que, como consecuencia de ese criterio, han de subsistir, por derecho propio; un número infinito de pequeños centros de población, creando un angustioso problema que interesa puntualizar exactamente.

En España, en un total de 9.260 Municipios, tenemos 3.034 que no exceden de 500 habitantes; 2.153 que oscilan entre los 501 y los 1.000, y 1.688 que, superando la última cifra, no pasan de los 2.000 habitantes (50). Agreguemos a esto que si el principio jusnaturalista se llevara a sus últimas y necesarias consecuencias, es decir, si se concediese categoría municipal a todas las entidades de población aglomerada, cualquiera que fuese su importancia, nos encontraríamos en España con 49.927 municipios, por to menos (51).

(50) Anuario Estadístico cit.; pág. 19.

(51) Esta cifra está formada por el total de ciudades, villas, lugares $\mathrm{j}$ aldeas 'que existen en España. Anuario Estadístico cit.; pág. 22. 
Pero ello, que es mucho, no dice bastante. Una entidad jurídica no es un fin por sí misma; es simplemente un medio para lograr finalidades, que en esta materia han de ser el mayor bienestar del vecindario. La Ley establece un mínimo de servicios que obligatoriamente han de atender los Ayuntamientos (52), constituyendo los mismos la menor asistencia y protección debida por las Corporaciones municipales a sus administrados, la estricta razón de ser de las mismas. El ineludible cumplimiento de dichos servicios determina la mínima potencia económica exigible a una municipalidad. Ahora bien, a la inmensa mayoría de los Municipios españoles no les es dado hacer frente a casi ninguno de esos deberes básicos; muchas de las citadas entidades carecen de capacidad para atender a ringún fin. Subsisten las mismas en aras de un principio teórico de romanticismo político, pesando sobre su vecindario la condena de vivir eternamente al margen de la civilización y del progreso, de carecer de los servicios públicos más elementales, simplemente porque al legislar se tomó partido por determinada doctrina filosófica, sin pararse a considerar cuál pudiera ser el alcance práctico de la misma al ponerse en contacto con la realidad nacional.

Veamos algunas cifras para justificar este aserto. Con arreglo a los datos más recientes que poseemos (53), existían en España en 1925 un total de 3.324 Ayuntamientos con presupuestos ordinarios menores de 10.000 pesetas, lo cual, en relación a los 8.692 Ayuntamientos de régimen común (54), supone un 34,94 por 100; de ellos, 1.258 presupuestos no alcanzan a 5.000 pesetas. Hay además 1.458 Ayuntamientos con cifras presupuestarias que se quedan por debajo de las 15.000 pesetas.

No vale la pena de insistir, pues estos datos se comentan solos. ¿Qué es asequible con esas cantidades irrisorias?; ¿qué pueden llevar a cabo esos 4.782 Municipios españoles-"naturales"-con una disponibilidad anual inferior a 15.000 pesetas y algunos-231-con menos de 3.000? Estrictamente mal pagar un Secretario.

Brevemente haremos notar otra consecuencia ineludible del sistema: la autonomía. Carrera Jústiz (55) establece la evolución que conduce a ella. "Siendo éste el proceso natural de los grandes agre-

(52) Artículos 110 al 112, 114 y 115 de la Ley Municipal de 1935.

(53) Dirección General de Administración.-Anuario de la Vida Local de España. 1924-1925. Madrid, 1925; tomo II, págs. 17 y 18.

(54) No se olvide que estos datos se refieren a 1925 y que no comprenden las Provincias Vascongadas y Navarra, que disfrutaban entonces de un régimen económico particular.

(ว5) Carrera Jástiz, ob. cit.; pág. 33. 
gados sociales-dice-, es evidente que las partes que a su formación concurrían para mejorar, cada una de ellas, su peculiar condición, jamás declinaban su propia personalidad, es decir, su propia. autonomía, sino que sólo se requería cierto orden de dejaciones, nada más que las que fueran necesarias para que el agregado mayor resultase en condiciones de cumplir sus fines en bien de la comunidad toda... En cada una de estas esferas [familia, municipio] hay, y sigue habiendo, un estado perfecto, es decir, una manera perdurable de estar o de existir... El Municipio es el Estado en lo local...". Fl preámbulo del Estatuto de 1924, coincidiendo con este criterio, empareja la autonomía con el concepto de entidad natural.

Ahora bien, no debe perderse de vista que dentro de la orientación totalitaria del Estado nuevo, el Municipio natural, y por lo tanto autónomo, se consideraría incompatible con el régimen. Véase cómo se plantea la cuestión. Kelsen (56) afirma que "la doctrina dominante suele autorizar la autonomía, situándola en una tal oposición a la administración del Estado, que quedan separadas como cosas enteramente distintas la administración autónoma y la administración estatal". Dentro de esa tendencia, como ya hemos indicado, Carnevali (57) niega al Municipio el carácter de órgano del Estado y afirma que se halla situado fuera de la jerarquía estatal. Finalmente, conviene tener en cuenta el concepto que Merkl (58) forma de la autonomía, considerándola como "una independencia caracterizada por una personalidad jurídica y por la exclusión del derecho de dar órdenes en los asuntos de la administración autónoma por parte de cualquier autoridad que se halle fuera de dicha entidad".

Pero esos criterios no caben en el sistema absolutamente integral del Estado totalitario, incompatible fundamentalmente-con todo sistema pluralista. "Para el fascismo-como ha dicho Mussolini (59) -el Estado es un absoluto frente al cual individuos y grupos 'son relativos". El totalitarismo y la concepción natural del $\mathrm{Mu}$ nicipio se excluyen mutuamente.

VIII. Nos ocuparemos ahora de la postura real que adoptan ante el problema las legislaciones inspiradas en ideas jusnaturalistas. ¿Cómo desenvuelven las mismas esos principios?, ¿cómo abordan las

(56) Kelsen, ob. cit; pág. 240.

(57) Carnevali, ob. cit; pág. 64 .

(58) Merkı (Adolfo).-Teoría General del Derecho Administrativo. Versión española. Madrid, pág. 449.

(59) Mussolini (Benito).-Scritti e discorsi. Milano, 1934; vol. VIII, página 84 . 
dificultades prácticas que hemos apuntado anteriormente? En honor de la verdad, debemos hacer constar aquí que las afirmaciones teóricas de aquellas leyes quedan muy mal paradas al desarrollarse en preceptos concretos integrados orgánicamente en el conjunto del sistema.

Ya hemos expuesto el criterio general del jusnaturalismo: el $\mathrm{Mu}-$ nicipio existirá tan sólo donde la naturaleza lo engendre, sin que pueda establecer la 'Ley ningún requisito que desvirtúe esa personalidad natural. Y sin embargo, es la propia Ley quien, después de sentar ese principio condiciona y restringe la posibilidad de existencia de las entidades municipales. Veamos cuáles son las exigencias de la de 1935 para reconocer esa personalidad:

1. Que posean recursos propios para cumplir sus fines peculiares. (Párrafo primero del artículo 7. ${ }^{\circ}$ )

2.9 Que no exista contigüidad material de edificaciones entre el Municipio matriz y el segregado. (Párrafo primero del artículo $9 .^{\circ}$ )

3. Que se 'les adjudique un territorio proporcionado a su población. (Párrafo segundo del art. 9. ${ }^{\circ}$ ) (60).

Compárese esa sistematización de preceptos de la Ley de 1935 con 'el artículo $2 .^{\circ}$ de la Ley de 1877 (61) y se comprobará que las diferencias entre el criterio legalista de ésta última y el naturalista de la primera, si se prescinde de la existencia de un mínimo de población, son absolutamente nulas. Es Municipio, pura y simplemente, aquél que cumple los requisitos que la misma exige.

A ello hay que añadir que no sólo condiciona la Ley la existencia de las entidades municipales, sino que se atribuye la facultad de mermar la capacidad de las mismas por la tutela y de poner fin a su existencia cuando no lleven a cabo la misión que la propia Ley les confía (62). Simplemente por deudas puede ser disuelto un $\mathrm{Mu}$ -

(60) Coinciden esencialmente las disposiciones citadas con los artículos 16 del Estatuto de 1924 y 16 del Reglamento de Población y Términos Municipales de 2 de julio de 1924.

(61) El art. 2.9 de la Ley de 1877 dice así en la parte que nos interesa:

"Son circunstancias precisas en todo término municipal:

1.9 Que no baje de 2.000 el número de sus habitantes residentes.

$2 .^{a}$ Que tenga o se le pueda señalar un territorio proporcionado a su poblacion.

3." Que pueda sufragar los gastos municipales obligatorios con los recursos que las leyes autoricen."

(62) "Art. 241. Si después de rehabilitada una Hacienda municipal incurriese por segunda vez el Ayuntamiento en las causas que determinan la tutela, el Ministro de la Gobernacion. de acuerdo con el Consejo de Ministros, podrá acordar, dando cuenta a las Cortes, la supresión del Municipio y su incorporacion a otro limitrofe." Ley Municipal de 1935. Coincide esencialmente.con el artículo 287 del Estatuto de 1924. 
nıcıpıo (6亏̃), y ello nos demuestra que cualquiera que sea ei criterio en que se inspire un sistema municipalista, la creación y ia subsis. tencia de una entidad municipal estará condicionada al cumplimiento de las condiciones por la Ley establecidas.

Las legislaciones de tipo jusnaturalista ofrecen todavía más sorprendentes contrasentidos. Se pronuncian las mismas, recogiendo el fundamento básico de la doctrina en que se inspiran, en la necesidad de reconocer los hechos sociales de la naturaleza, sin admitir organismos de artificio. Ahora bien, ¿que significan esas entidades cuasi municipales que con la denominación de entidades menores se cılocan por el Estatuto de 1924 y por la Ley de 1935 entre la fanilia y el Municipio? El criterio ortodoxo determina que el Municipio es el segundo grado de las sociedades fundamentales, estandn constituído por la reunión de varias familias. ¿Cuál es, pues, la justificación de esos círculos intermedios?; ¿ en qué se diferencian, en la Ley de 1935, un Municipio de una Entidad menor?; porque si con arreglo al artículo 2. de la misma constituyen las Entidades menores "núcleos separados de población... con territorio propio y... peculiares derechos e intereses colectivos"; y de acuerdo con el artículo $3 .^{\circ}$ poseen una capacidad jurídica de idéntica extensión y contenido que el Municipio, no se nos alcanza cuál pueda ser la diferenciación entre unos y otras, y cómo ha podido la Ley, en flagrante contradicción consigo 'misma, reducir la capacidad de obrar de esos ver: dareros Municipios, a quienes, por otra parte, reconoce en principio una plena capacidad de goce de carácter estrictamente municipal.

Estas entidades secundarias, o serán Municipios, en cuyo caso una Ley jusnaturalista no puede arrebatarles esa consideración, o no serán nada, porque la doctrina básica del sistema no admite organismos intermedios entre Municipio y Estado. Como hemos dicho en otro lugar (64), "son esos seudomunicipios una creación artificial y un mentís a los principios naturalistas en que la Ley se inspira; si existe naturalmente el Municipio en donde quiera que se dé el hecho de la convivencia humana, sin que la norma jurídica pueda hacer más que reconocerlo, ¿con qué derecho establece la Ley graduaciones y categorías e interviene para capitisdisminuir su capa cidad y para determinar caprichosamente en dónde termina el $\mathrm{Mu}$. nicipio y en dónde comienza la Entidad menor,

Todo esto, con las agrupaciones forzosas de Municipios, y aún $=n$ determinados aspectos con las voluntarias, no son en resumen 
más que un eonjunto de difíciles equilibrios verificados para poner de acuerdo las realidades prácticas de la vida local con unas doctrinas bien alejadas de las mismas.

IX. El error fundamental del jusnaturalismo procede de la confusión que establece entre dos factores, que deben considerarse por separado y que aquel sistema involucra. El complejo que denominamos Municipio lo integran, como ya hemos apuntado, dos elementos distintos que la referida escuela no ha sabido percibir y diferenciar: la agrupación humana-hecho social-y el Municipio propiamente đicho-institución jurídica-. Taparreli, sagazmente, ya vislumbró esa dualidad de contenido, aunque sin alcanzar a deducir de ellas las obligadas consecuencias; así nos habla de "los Comunes..., asociación más natural e italiana, y los Municipios, otra más artificial y latina" (65).

La elave del problema descansa en esta distinción. Los hombres - no la naturaleza-, como consecuencia de un conjunto bien complejo de diversas situaciones económicas e históricas, constituyen grupos sociales con localizaciones geográficamente distintas, que no se determinan con arreglo a un molde uniforme. sino que presentan una diversidad de caracteres que no dependen sólo de las circunstancias originarias, sino de todas aquellas otras que influyeron en su posterior desenvolvimiento. Esas comunidades se ofrecen prácticamente en una gama de infinitas variantes en cuanto a necesidades y a medios, y diversas habrán de ser, por lo tanto, las modalidades jurídicas adecuadas para satisfacerlas. El Estado y sólo el Estado, única sociedad total y soberana, será la llamada a determinar cuál sea la forma más adecuada en cada caso para que los elementos humanos en relación de convivencia vecinal puedan cumplir mejor aquellas finalidades inmediatas que desbordan de la acción individual de los mismos, y para ello, claro está, deberá el propio Estado, prescindiendo de supuestos derechos naturales de aquellas agrupaciones, establecer su sistema orgánico de administración local, tomando como punto de partida las siguientes premisas fundamentales:

a) Su soberanía total y absoluta, que no puede admitir copartícipes ni condicionamiento alguno.

b) Las circunstancias políticas del país y los antecedentes históricos de los diversos centros de población.

c) La capacidad económica de las agrupaciones sociales.

Planteado el problema a base de la distinción en el Municipio en-

(65) Taparelli, ob. cit.; tomo IV, pa.g. 400. 
tre elemento jurídico y social, la cuestión que debatimos quedará totalmente aclarada. Resultará de este distingo el pleno respeto y protección por parte del Estado del hecho de la convivencia humana, en. donde quiera que la misma se presente, pero sin que de ello puedan derivarse consecuencias que afecten al régimen orgánico estatal. I a conveniencia de conectar esas agrupaciones sociales, mediata 0 inmediatamente, con un organismo de gobierno, es cuestión-insistimos en ello—que afecta exclusivamente a la soberanía del Estado y: que este resolverá con plena libertad, atendiendo principalmente a un factor decisivo entre todos los enumerados con anterioridad: el que dichas agrupaciones posean la capacidad económica precisa para llevar a cabo las finalidades mínimas que el Estado les atribuya.

En este sentido se enderezan las tendencias de las más modernas legislaciones municipales de hoy día. No preocupa para nada el supuesto jusnaturalista. Se actúa en un sentido positivo, real, al margen de romanticismos y prejuicios doctrinales. Fundamentalmente, es Municipio quien puede serlo, quien posee vitalidad propia para cumplir sus obligaciones mínimas. No se habla de derechos originarios, sino simplemente de deberes. El texto único italiano de 1934, en su artículo 33 , si bien fija un mínimo de población para que pueda crearse una entidad municipal exige, sobre todo, que posea la misma "medios suficientes para atender adecuadamente los servicios públicos". La Ley alemana es aún más concreta: "El territorio de cada Municipio-dice el artículo 4 de la de 1935-debe determinarse de tal modo... que quede a salvo la aptitud del Municipio para cumplir sus deberes..." El Código Administrativo portugués de 31 de diciembre de 1936, en su artículo $8^{\circ}$, sólo admite la constitución de nuevos: Municipios cuando se desprenda su necesidad de "razones económicas y administrativas... y disponga de los ingresos suficientes para hacer frente a sus óbligaciones". Las modernísimas legislaciones democráticas también mantienen tendencia análoga, que no es patrimonio exclusivo de las de tipo totalitario: la Ley Municipal de Yugoslavia de 14 de marzo de 1933, en su ártículo $3 .^{\circ}$, ha manifestado su voluntad de crear núcleos comunales "de volumen proporcionado a las necesidades de la vida local", y la Ley de Polonia de 23 de marzo de 1933 , en el artículo 10 de la misma. determina que "el tamaño de la comunidad ha de corresponder a los intereses comunes... y asegurar a la comunidad una aptitud bastante para la ejecución de sus tareas".

Ello trae como consecuencia la desaparición absoluta en las defii4 niciones generales contenidas en las nuevas leyes de toda alusión a 
derechos originarios o a características naturales. La Ley alemana dice a este respecto en su artículo $10^{\circ}$ que "los Municipios agrupan las fuerzas vivas de los habitantes de la comunidad con el fin de llevar a cabo los objetivos de carácter público a su cargo"; la Ley portuguesa hace constar en su artículo 13 que "el Municipio es un agregado de personas residentes en la circunscripción municipal con intetereses comunes".

De ahí se deriva la nueva política, enderezada a suprimir entidades anémicas que subsistían solamente por imperativos cuyo origen era un principio puramente especulativo. En 3 de julio de 1939 el Ministro alemán del Interior dictaba un decreto en virtud del cual han desaparecido 15.000 minúsculos Municipios, incapaces de hacer frente a sus obligaciones fundamentales.

Fernando Albi

Secretario del Ayuntamiento de Bilbao 